Type of the Paper (Article)

\title{
Social media addiction and emotions during the disaster recovery period? - The moderating role of post-COVID timing.
}

\author{
Dewan Muhammad Nur -A Yazdani ${ }^{1}$, Tanvir Abir ${ }^{2}$, Yang Qing ${ }^{3}$, Jamee Ahmad ${ }^{4}$, Abdullah Al Mamun ${ }^{5}$, Noor \\ Raihani Zainol', Kaniz Kakon7, Kingsley Emwinyore Aghos, Shasha Wang9
}

1 MSc, Research Associate, Creative research and consultancy, Bangladesh; dewanyazdani@gmail.com;

$2 \mathrm{PhD}$, Associate Professor, Department of Business Administration, Faculty of Business \& Entrepreneurship (FBE), Daffodil International University, Dhaka, Bangladesh; t.abir73@gmail.com;

3 UCSI Graduate Business School, UCSI University, 56000 Cheras, Kuala Lumpur, Malaysia. Email: 1001437164@ucsiuniversity.edu.my;

4 MBA, Senior Lecturer, College of Business Administration-CBA, International University of Business, Agriculture and Technology -IUBAT University, Dhaka 1230, Bangladesh; jamee.ahmad@iubat.edu;

5 PhD, UKM - Graduate School of Business, Universiti Kebangsaan Malaysia, 43600, UKM Bangi, Selangor Darul Ehsan, Malaysia; almamun@ukm.edu.my

$6 \mathrm{PhD}$, Faculty of Entrepreneurship and Business, Universiti Malaysia Kelantan, Kota Bharu 16100, Malaysia; raihani@umk.edu.my;

7 MA, Assistant Professor, Department of Philosophy, College of Arts and Sciences-CAAS, International University of Business Agriculture and Technology - IUBAT University, Dhaka 1230, Bangladesh; kanizk2@yahoo.com;

8 PhD, Lecturer in the School of Advertising, Marketing and Public Relations at the QUT Business School, Queensland University of Technology; shasha.wang@qut.edu.au; and

9 PhD,-Associate Professor, School of Science and Health, Western Sydney University, Campbelltown, NSW 2560, Australia. African Eye and Public Health Research Initiative; African Vision Research Institute, Discipline of Optometry, University of KwaZulu-Natal, Westville Campus, Durban, 3629, South Africa; K.Agho@westernsydney.edu.au

* Correspondence: Dr. Tanvir Abir, Associate Professor, Department of Business Administration, Faculty of Business \& Entrepreneurship (FBE), Daffodil International University, Dhaka, Bangladesh; t.abir73@gmail.com; Cell no.: +8801972520034.

\begin{abstract}
Social media addiction has attracted the attention of researchers especially during the COVID era because negative emotions generated from the pandemic may have increased social media addiction. The present study aimed to investigate the role of negative emotions and social media addiction on health problems during and after the COVID lockdown. A survey was conducted with 2926 participants aged between 25 and 45 years. The data collection period was between 2nd September and 13th October 2020. Partial Least Square Structural Equation Modeling was conducted for data analysis by controlling the respondents' working time, leisure time, gender, education, and age. Our study showed that social media addiction and time spent on social media impact health. Interestingly, while anxiety about COVID increased social media addiction, fear about COIVD reduced social media addiction. Also, long working hours contributed most to people's health issues, and its impact on social media addiction and hours was much higher than negative emotions, where males faced more health challenges than females. The impacts of negative emotions generated by the COVID on social media addiction and health issues should be reconsidered. Government and employers' control of people's working time stress should prioritize solving social media addiction-related issues.
\end{abstract}

Keywords: social media, addiction, anxiety, fear, health issues

\section{Introduction}

Social media, being a fundamental part of people's lives, leaves an immense impact on every aspect. Scrolling and checking social media has become almost a daily routine of 
over half of the world's population's daily activities. According to statistics, in the last five years, the number of social media users has almost doubled, increasing from 2.2 billion in 2015 to 4.5 billion at present. This number of users is increasing at an incredible rate [1]. The number of social media users has also increased in Bangladesh by 9.0 million (+25\%) between 2020 and 2021 [2]. The number is rising because social media is the only webbased platform where people with similar backgrounds, interests, activities, and connections can be linked [3]. Besides, the financial ability of people to buy social media (Facebook, Snapchat, Twitter, WhatsApp, Instagram etc.) accessible devices such as smartphones and laptops has increased, resulting in the increasing number of social media users [4]. As social media creates ample opportunities for people to correspond virtually, temporal and partial boundaries notwithstanding [5] and promotes communication and sharing of images and videos amongst social network users, individuals of all ages around the world are taking this advantage [6].

Moreover, the ongoing COVID-19 pandemic caused by Novel CoronaVirus significantly influences every individual's lifestyle [7, 8]. Various governments are adopting different policies such as lockdown, quarantine etc., to curb the spread of the virus by keeping people indoors [9]. Working from home and virtual education practices have forced people to spend a long time on social media in order to fulfill their needs for work-and disaster-related information, entertainment, and interpersonal communication [10]. Despite the fact that social media plays an undeniably beneficial role in sustaining contact and relationships among individuals, its increased usage is sufficient to result in addiction [11]. A past study has revealed that the level of social media addiction depends on the daily time devoted to the social media platform, and addiction is increased by more frequent daily visits to social media profiles [12]. Another study found an important association between the daily average internet usage time of high school students and social media addiction[13]. However, while social media usage may not always be harmful, some people get addicted to and use them extremely or obsessively [14]. Experts have observed the harmful effects of long-term addiction, extreme and obsessive social media usage and showed that such a level of social media addiction might result in psychological, physiological and productivity issues [15].

There is evidence that obsessive social media usage can impact users' psychological, cognitive, perceptual, and physiological well being. Addicted social media users may have withdrawal feelings, relational issues and other issues as well [16]. Recent research has found that many people have become addicted to social media due to the COVID-19 epidemic [11], creating several physical health issues such as headaches, sleeping disorders, stomach ailments, and exhaustion $[17,18]$. It has been found that using different online platforms, especially social media, shopping websites - whether for essential items or shopping items has increased a lot during COVID-19. This change in the excessive use of digital media has brought numerous physical disorders [19] and left adverse effects on the usual physical activities among the general population [20]. It has been established that despite social media being an essential and integral part of people's lives for day-to-day work and communication, the impact caused by its extensive use on health cannot be ignored [21].

Social media addiction may create significant emotional problems as well. Fear resulting from abundant information on social media regarding the coronavirus disease and the 'lockdown' situation caused high levels of uncertainty and raised the level of stress, anxiety, and depression (sometimes leading to suicides) among people worldwide [22-24].

In a nutshell, social media usage hours have been found to be strongly associated with creating social media addiction, and social media addiction causes several physical and psychological issues. Some past studies from Bangladesh have assessed the effect of social media and smartphone use vis-à-vis the COVID-19 (the virus). For instance, a study by Islam and colleagues [25] investigated complicated smartphone use and complex social media use among College and University students in Bangladesh during the COVID-19 pandemic. Findings of that study indicated that problematic social media use was linked 
to poor psychological well being (such as anxiety and depression) and other factors (particularly lower age, poor sleep) during the pandemic, which further suggested the demand for interventions that includes virtual awareness programs among College and University students. The present study mainly focused on social media users' health and psychological problems among workers across all the nine districts of Bangladesh after the COVID-19 restriction period imposed by the government of Bangladesh. This study will inform future similar studies and the establishment of new policies seeking to find out how Bangladeshi workers might be affected by social media use during the COVID19 pandemic. Additionally, the results of the study could assist efforts to disseminate behavioral health information on social media.

Reviewing the relevant literature established that social media addiction brings about physical and psychological changes. Consequently, the present research focused on both psychological and physical issues related to social media addiction. Based on the background to the study above, the following research hypotheses were propounded:

\subsection{Hypotheses}

Based on the research purposes and discussion above, the current study established the following research hypotheses:

Hypothesis 1 (H1): Anxiety increases with social media addiction.

The COVID-19 pandemic is an epidemiologic and health crisis, since it causes extensive psychological issues such as stress, anxiety, depression, trauma, panic, insomnia, death distress, anger, psychosis, boredom, and suicide [26-28].

Hypothesis 2 (H2): Fear increases with social media addiction.

However, the pandemic has underscored the downside of social media by showing that uncontrolled use is propagating panic, fear, and misinformation about COVID19 among mass populations [29]. There has been great fear of contracting the virus among many people, because of the world-wide continuous rise in the death toll due to the virus [30]. Excessive social media use has been identified as one of the major reasons behind this rise in fear. Social media platforms have become home to atrocious and sometimes erroneous information associated with the virus (Islam et al., 2020). Social media users spread rumors, conspiracy theories, and even inaccurate calculations of COVID-19 cases and deaths, propagating fear among the masses [29]. Hypothesis 3 (H3): Social media addiction increases with social media usage hours. According to a past study [12], social media addiction has risen significantly, as has the amount spent online on a routine basis. The obsession is exacerbated by the more frequent daily visits to social media accounts.

Hypothesis 4 (H4): Social media addiction increases physical health issues.

Past research has revealed that uncontrollable usage of social media has an effect on physical and mental health, such as cardio-metabolic health, sleep, affect, self-esteem, wellbeing and functioning, particularly in adolescents [31].

Hypothesis 5 (H5): Social media usage hours increase physical health issues.

It is evident; and this is inspired by research that 'internet addiction' is principally linked to increased social media or gaming activities [32].

Hypothesis 6 (H6): Time plays a moderating role in the proposed relationships. Specifically, a) the relationship between anxiety and social media addiction will be more substantial overtime; b) the relationship between fear and social media addiction will be more substantial overtime; c) the relationship between social media addiction and social media usage hours will be more robust over time and $d$ ) the relationship between social media addiction and physical issues will be more potent over time, after the disaster.

\subsection{Conceptual Framework}

A conceptual framework is a system of concepts, assumptions, expectations, beliefs, and theories supporting and informing research (Maxwell, 2005, p. 33). According to the background and objectives of the study and based on the research hypotheses, 
the researchers have identified the dependent and independent variables of the present study and showed their hypothesized relationship in the following diagram.

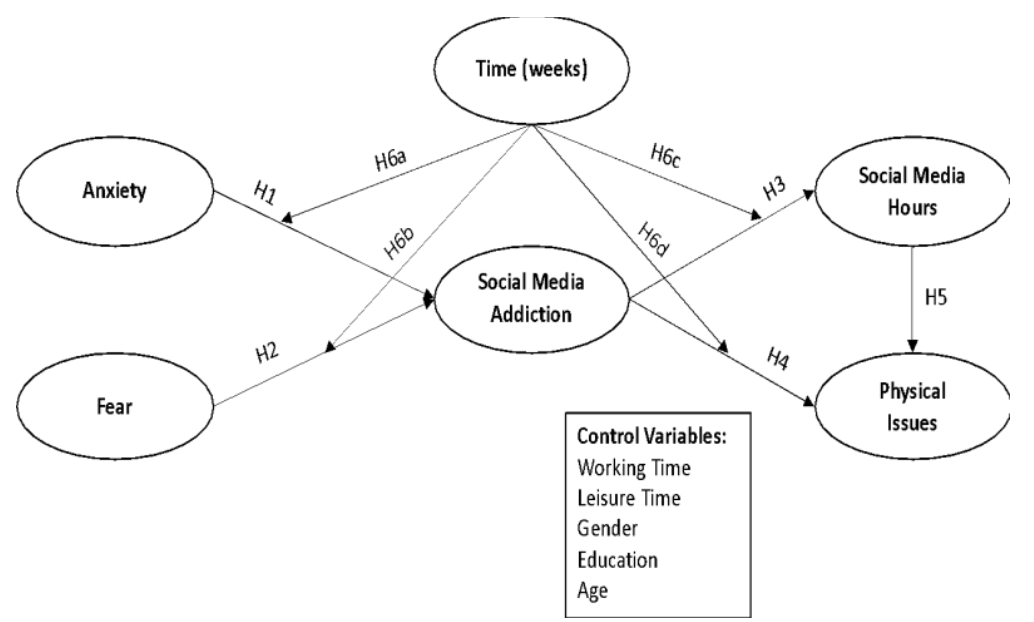

Figure 1: Conceptual framework for the model

\section{Materials and Methods}

This study embraced a sequential cross-sectional design. Data were collected for a period spanning six weeks from $1^{\text {st }}$ August 2020 to $15^{\text {th }}$ September 2020. This period was chosen because of the sad change in people's lifestyle of being isolated from the outside world due to the pandemic and obtaining most of their necessities using a virtual medium. Furthermore, during this period, the situation was getting normal, participants resumed their work physically, and offices opened after the COVID-19 lockdown. Consequently, a new normal life was being experienced, participants with technology, the internet, and social media became indispensable.

The Institutional Review Board of the International University of Business, Agriculture and Technology (IUBAT), Dhaka, Bangladesh, granted permission for this study (IUBAT/AR/2021/002). The study followed the principles of the Helsinki Declaration, as updated in Fortaleza. Before completing the questionnaire, all participants were informed about the study's specific goal, and consent was obtained from all participants through an online preamble.

To avert repeated responses, and also to make sure that the data were valid to some extent, respondents were permitted to complete the survey only once; this was because of the fact that data were limited to their IP addresses and device. Respondents had the option of terminating the survey at any time they desired. Furthermore, we ensured that the data were anonymous and confidential.

\subsection{Statistical Methods}

Smart PLS 3 was used to analyze this study through a Partial Least Square Structural Equation Modeling (PLS-SEM) approach. There are several reasons for choosing this approach. These include its ability to deal with complex multivariate models and variables with different scales, explore theories, and test multiple mediators simultaneously [33]. We used the SmartPLS to have the individual parameters and the significance level. [34] In this study, the first step was to create groups according to the categorical variables of interest, including age, gender, education, working time and leisure time and this was followed with data analysis of the measurement reliability, validity for the latent reflective construct and social media addiction were examined by several indicators as suggested by Malak and colleagues [35]. Next, the second stage involved assessing the structural model correlations and hypotheses testing with significance levels. Model estimation was conducted with r2, Q2 and effect size describes the path effect from exogenous construct to endogenous construct [34]. Next, the path 
coefficients of the groups were analyzed to determine if they were significantly diverse from each other based on the guidelines proposed by Henseler et al. [36].

\subsubsection{Procedure}

This cross-sectional survey was conducted using an online platform on all 8 divisions of the country. A self-administered online survey was conducted by using social media, in which 2926 out of 3,500 respondents correctly completed questionnaires. The survey questionnaire was developed based on different internet, and social media related scales, namely, Internet Disorder Scale (IDS-15), Social Media Disorder Scale (SMDS), UCLA Loneliness Scale\& the Generalized Problematic Internet Use Scale (GPIUS).

\subsubsection{Descriptive analysis}

The data were collected over six weeks, starting from week $1\left(^{\text {nd }}-8^{\text {th }}\right.$ September); followed by week 2 ( $9^{\text {th }}-15^{\text {th }}$ September $)$, week $3\left(16^{\text {th }}-22^{\text {nd }}\right.$ September $)$, week 4 (23 $^{\text {rd }}-29^{\text {th }}$ September $)$, week 5 (30 $30^{\text {th }} 6^{\text {th }}$ October $)$ and week 6 ( $7^{\text {th }}-13^{\text {th }}$ October $)$ in that order. Variables considered in the data collection included: gender, age, education level, work time and leisure time. A structured questionnaire was used for that purpose. Each variable in the questionnaire was coded; for instance, for gender, the male was coded " 1 ", the female was coded "2", and the other was coded "88". For level of education, Under SSC, SSC or equivalent, HSC or equivalent, Graduate, Post Graduate, Doctorate, Post Doctorate and Other were coded " 1 ", " 2 ", " 3 ", " 4 ", “ 5 ", " 6 ", " 7 " and " 88 " respectively.

\subsubsection{Measurements}

There was a total of 15 items in the IDS-15; measurement and conceptualization of internet addiction were made based on the four distinct latent domains: 'Escapism and dysfunctional emotional coping', 'Withdrawal symptoms', 'Impairments and dysfunctional self-regulation', and 'Dysfunctional Internet-related self-control'. The SMD is a short and simple scale to diagnose a disorder in social media use. Social Media may be described as "any website where messages are posted for a group of people ". Examples are: Facebook, Twitter, YouTube and Instagram, to mention but a few. The UCLA loneliness scale is a 20-item rating scale that measures the subjective experience of loneliness on a four-point Likert scale. The Generalized Problematic Internet Use Scale (GPIUS) [37] was one of the first scales established to measure cognitive and behavioral symptoms related to PIU from a multidimensional perspective. The negative factor outcome appraises the negative effects associated with internet use.

\section{Results}

Table 1: Descriptive Analysis

\begin{tabular}{|c|c|c|c|c|c|c|}
\hline \multirow[b]{2}{*}{ Time variable } & \multirow[b]{2}{*}{$\begin{array}{c}n=292 \\
6\end{array}$} & $\begin{array}{l}\begin{array}{l}\text { Gender } \\
\text { (males) }\end{array} \\
\end{array}$ & \multirow{2}{*}{$\begin{array}{l}\text { Age (years) } \\
\text { Mean (sd) }\end{array}$} & Education & \multirow{2}{*}{$\begin{array}{l}\text { Work Time } \\
\text { Mean (sd) } \\
\text { (25th, 75th } \\
\text { percentile) }\end{array}$} & \multirow{2}{*}{$\begin{array}{c}\text { Leisure time } \\
\text { Mean (sd) } \\
\text { (25th, 75th } \\
\text { percentile) }\end{array}$} \\
\hline & & $\begin{array}{c}\mathrm{n}=(1773, \\
60.7 \%)\end{array}$ & & $\begin{array}{l}\text { Mean (sd) } \\
\text { (25th, 75th } \\
\text { percentile) }\end{array}$ & & \\
\hline Week1 (2-8 Sep) & 631 & 60.9 & $\begin{array}{c}33.4(6.4)(30 \\
38)\end{array}$ & $4.2(0.79)(4,5)$ & $2.8(1.3)(2,3)$ & $3.8(1.8)(2,5)$ \\
\hline Week2 (9-15 Sep) & 406 & 55.9 & $32.6(7.7)(28,38$ & $4.1(1.0)(4,5)$ & $2.6(1.4)(1,3)$ & $3.4(1.9)(2,5)$ \\
\hline Week3 (16-22 Sep) & 674 & 55.4 & $\begin{array}{c}34.5(6.3)(30 \\
39)\end{array}$ & $4.4(0.9)(4,5)$ & $2.5(0.9)(2,3)$ & $3.6(1.8)(2,5)$ \\
\hline Week4 (23-29 Sep) & 223 & 71.8 & $\begin{array}{c}33.5(5.6)(30 \\
39)\end{array}$ & $4.5(0.6)(4,5)$ & $2.9(0.5)(3,3)$ & $4.7(1.0)(5,5)$ \\
\hline $\begin{array}{l}\text { Week5 (30 Sep- } 6 \\
\text { Oct) }\end{array}$ & 665 & 64.4 & $31.7(7.0(28,38)$ & $4.2(0.7)(4,5)$ & $2.8(1.1)(2,3)$ & $3.8(1.7)(2,5)$ \\
\hline Week6 (7-13 Oct) & 327 & 62.4 & $\begin{array}{c}34.1(5.9)(30 \\
39)\end{array}$ & $4.3(0.7)(4,5)$ & $3.0(1,4)(3,3)$ & $4.2(1.7)(3,5)$ \\
\hline
\end{tabular}


Table 1 presents the results of the descriptive analysis of the variables controlled for in our analysis. According to the table, 1, 773 males were samples, representing $60.7 \%$ of the total. In week $1,60.9 \%$ of participants were male. The mean (standard deviation (sd)) of their age was 33.4 years $( \pm 6.4)$; and the 25 th and 75 th percentiles were 30 and 38 , respectively. The corresponding means and sds of the ages of participants for weeks 2,3 , 4,5 and 6 were: 32.6 (7.7), 34.5 (6.3), 33.5 (5.6), 31.7 (7.0) and 34.1 (5.9) years, respectively. The mean score for education (sd) was $4.2(0.79)$, indicating that the participants were either Graduates or Postgraduates, with one-quarter of them being Graduates and threequarters being Postgraduates. In week 1 , the mean score (sd) for work and leisure were 2.8 and 3.8, respectively, implying that the corresponding 25th and 75th percentiles were 1.3 and 2.3 weeks; 1.8 and 2.5 weeks, respectively.

\subsection{Hypotheses Tests}

The Chronbach's Alpha and Composite Reliability were 0.78 and 0.86 , respectively. These were both greater than the cut-off point of 0.6, confirming the reliability of the measurements. To achieve convergent validity, factor loadings should be greater than 0.7 [38]. The factor loadings of the four items: "Do you spend a lot of time thinking about social media or planning to use social media?" "Do you feel urges to use social media more and more?" "Do you become restless or feel troubled if unable to use social media?" and "Do you use social media so much that it could cause a negative impact on your job or studies?" were $0.83,0.81,0.73$ and 0.72 , respectively. The Average Variance Extracted (AVE) of the latent construct of social media addiction was 0.60 , which was greater than the cut-off point of 0.50 . Therefore, convergent validity was achieved. The heterotrait-monotrait ratio of correlations (HTMT) values ranged from 0.01 to 0.85 across all single-indicator constructs in examining discriminant validity. The reflective latent construct was lower than the cut-off point of 0.9 [39]. To examine the common method bias, Variance Inflation Factor (VIF) should be lower than 3.3 [40], and all of the VIFs ranged from 1.0 to 1.36 .

To assess the formative construct, weights of the indicators should be significant without collinearity problems [41]. The indicators were all significant $(\mathrm{p}<0.05)$ without collinearity issues (VIF<3.3): back pain (weight $=0.40, \mathrm{t}=15.65, \mathrm{p}<0.001, \mathrm{VIF}=2.36$ ), numbness (weight $=0.45, \mathrm{t}=18.20, \mathrm{p}<0.001, \mathrm{VIF}=1.90$ ), and headaches (weight $=0.28, \mathrm{t}=10.69, \mathrm{p}<0.001$, $\mathrm{VIF}=2.18)$.

\subsubsection{H1-H5 Test}

Before testing the moderation effect (H6), H1-H5 were tested without the moderator (weeks). As shown in Table 2, the model had good predictive accuracy (R2) and predictive relevance (Q2). According to Hair et al. (2011)'s suggestions on the R2 values, the model explained physical issues substantially $(75 \%)$, social media addiction moderately $(60 \%)$, and social media hours moderately (57\%) [33]. As suggested by Geisser (1974) [42], Q2 values greater than 0 represent good predictive relevance, and all of the Q2 values were greater than 0.35. 3.2.

Table 2: Hypotheses Tests (H1-H5)

\begin{tabular}{llcc}
\hline \multicolumn{1}{c}{ Tests } & $\begin{array}{c}\text { No moderator } \\
\text { coefficient }\end{array}$ & t-values \\
\hline & Hypotheses Tests & & \\
H1 & Anxiety à Social Media Addiction & 0.19 & $6.83^{* * * *}$ \\
H2 & Fear à Social Media Addiction & -0.12 & $7.00^{* * *}$ \\
H3 & Social Media Addiction à Social Media Hours & 0.22 & $7.03^{* * * *}$
\end{tabular}




\begin{tabular}{lcc} 
H4 Social Media Addiction à Physical Issues & 0.44 & $20.37^{* * *}$ \\
H5 & 0.07 & $3.23^{* *}$ \\
Social Media Hours à Physical Issues & & \\
Control Variables & 0.01 & $0.83^{\mathrm{ns}}$ \\
Age -> Physical issues & 0.03 & $1.62^{\mathrm{ns}}$ \\
Age -> Social Media Addiction & -0.04 & $1.85^{*}$ \\
Age -> Social Media hours & -0.05 & $3.24^{* *}$ \\
Edu -> Physical issues & -0.06 & $3.07^{* *}$ \\
Edu -> Social Media addiction & 0.14 & $6.06^{* * *}$ \\
Edu -> Social Media hours & -0.03 & $2.63^{* * *}$ \\
Gender -> Physical issues & -0.03 & $2.26^{*}$ \\
Gender -> Social Media addiction & -0.02 & $1.49^{\text {ns }}$ \\
Gender -> Social Media hours & -0.21 & $7.91^{* * *}$ \\
Leisure Time -> Physical issues & -0.08 & $2.56^{* *}$ \\
Leisure Time -> Social Media addiction & -0.38 & $13.90^{* * *}$ \\
Leisure Time -> Social Media hours & 0.56 & $15.45^{* * *}$ \\
Work time -> Physical issues & 0.66 & $15.48^{* * *}$ \\
Work time -> Social Media addiction & 0.76 & $20.10^{* * *}$ \\
Work time -> Social Media hours & $\mathbf{R}^{2}$ & $\mathbf{Q}^{2}$ \\
Model Statistics & 0.75 & 0.57 \\
Physical issues & 0.6 & 0.36 \\
Social Media addiction & 0.57 & 0.57 \\
Social Media hours & & \\
\hline
\end{tabular}

ns= non-significant, ${ }^{*} \mathrm{p}<0.05^{* *} \mathrm{p}<0.01{ }^{* * *} \mathrm{P}<0.001$

Anxiety was positively associated with social media addiction (Path Coefficient $=0.19$, $\mathrm{t}=6.83, \mathrm{p}<0.001)$, and $\mathrm{H} 1$ was supported. Fear was negatively associated with social media addiction (Path Coefficient $=-0.12, \mathrm{t}=7.00, \mathrm{p}<0.001$ ), thus $\mathrm{H} 2$ was not supported. Social media addiction was positively associated with social media hours (Path Coefficient $=$ $0.22, \mathrm{t}=7.03, \mathrm{p}<0.001$ ), and $\mathrm{H} 3$ was supported. Social media addiction was positively associated with physical issues (Path Coefficient $=0.44, t=20.37, \mathrm{p}<0.001$ ), and H4 was supported. Social media hours were positively associated with physical issues (Path Coefficient $=0.07, \mathrm{t}=3.23, \mathrm{p}<0.001)$, and $\mathrm{H} 5$ was supported.

Among all the control variables, participants' work time played the most important role in driving physical issues (Path Coefficient $=0.56, \mathrm{t}=15.45, \mathrm{p}<0.001$ ), which was much stronger than social media addiction (Path Coefficient $=0.44$ ) and social media hours (Path Coefficient $=0.07$ ). Work time was also positively associated with social media addiction (Path Coefficient $=0.66, \mathrm{t}=15.48, \mathrm{p}<0.001$ ), which had a much stronger influence than anxiety (Path Coefficient $=0.19$ ) or Fear (Path Coefficient $=-0.12$ ). More interestingly, work time was strongly and positively associated with social media hours (Path Coefficient $=$ $0.76, \mathrm{t}=20.10, \mathrm{p}<0.001)$.

Education, gender and leisure time were also associated with physical issues. Participants with higher education tended to have fewer physical issues than those with lower or no schooling (Path Coefficient $=-0.05, t=3.24, p<0.01$ ). Females tended to have fewer physical issues (Path Coefficient $=-0.03, \mathrm{t}=2.63, \mathrm{p}<0.01$ ) than males. The more leisure time participants had, the fewer physical issues (Path Coefficient $=-0.21, \mathrm{t}=7.91, \mathrm{p}<0.001$ ).

Social media addiction was negatively associated with participants' education level (Path Coefficient $=-0.06, t=3.07, \mathrm{p}<0.01$ ). Females tended to have lower social media addiction 
than males (Path Coefficient $=-0.03, \mathrm{t}=2.26, \mathrm{p}<0.05$ ). The more leisure time participants had, the lower their social media addiction (Path Coefficient $=-0.08, \mathrm{t}=2.56, \mathrm{p}<0.01$ ).

Social media hours were negatively related to age, and older participants had fewer social media hours (Path Coefficient $=-0.04, \mathrm{t}=1.85, \mathrm{p}<0.05$ ). Participants with higher education tended to have more social media hours than their less-educated counterparts (Path Coefficient $=0.14, \mathrm{t}=6.06, \mathrm{p}<0.001)$. The more leisure time participants had, the fewer social media hours (Path Coefficient $=-0.76, \mathrm{t}=20.10, \mathrm{p}<0.001$ ).

\subsubsection{H6 Test}

To test the moderating role of time after the Covid lockdown, the variable time (weeks) was added to the model. Again, the model had good predictive accuracy (R2>50\%) and predictive relevance (Q2>0), as shown in Table 3. The interaction term of time and anxiety was positive and significant (Path Coefficient $=0.06, \mathrm{t}=3.84, \mathrm{p}<0.001$ ), and the positive association between anxiety and social media addiction was stronger over time (see Fig. 2a). Therefore, H6a was supported. The interaction term of time and fear was not significant ( $p>0.05)$, and time did not influence the relationship (see Fig. $2 b$ ). Therefore, $\mathrm{H} 6 \mathrm{~b}$ was not supported. The interaction term of time and social media addiction was positive and significant (Path Coefficient $=0.04, \mathrm{t}=2.50, \mathrm{p}<0.01$ ), and the positive association between social media addiction and social media hours was stronger over time (see Fig. 2c). Therefore, H6c was supported. The interaction term of time and social media addiction was negative and significant (Path Coefficient $=-0.02, \mathrm{t}=2.09, \mathrm{p}<0.05$ ), and the positive association between social media addiction and social media hours was weaker over time (see Fig. 2d). This result contradicted our prediction, and therefore, H6d was not supported.

Table 3: Hypotheses Tests (H6)

\begin{tabular}{|c|c|c|c|}
\hline & Tests & $\begin{array}{l}\text { With moderator } \\
\text { coefficient }\end{array}$ & t-values \\
\hline & Hypotheses Tests & & \\
\hline H6a & Time*Anxiety QSocial Media Addiction & 0.06 & $3.84^{* * *}$ \\
\hline $\mathrm{H} 6 \mathrm{~b}$ & Time*Fear $\square$ Social Media Addiction & 0.01 & $0.35^{\mathrm{ns}}$ \\
\hline H6c & Time* Social Media Addiction DSocial Media Hours & 0.04 & $2.50^{* *}$ \\
\hline \multirow[t]{5}{*}{ H6d } & Time* Social Media Addiction DPhysical Issues & -0.02 & $2.09^{*}$ \\
\hline & Model Statistics & $\mathbf{R}^{2}$ & $\mathbf{Q}^{2}$ \\
\hline & Physical issues & 0.75 & 0.57 \\
\hline & Social Media addiction & 0.61 & 0.36 \\
\hline & Social Media hours & 0.58 & 0.57 \\
\hline
\end{tabular}

ns $=$ non-significant, ${ }^{*} \mathrm{p}<0.05^{* *} \mathrm{p}<0.01^{* * *} \mathrm{P}<0.001$ 

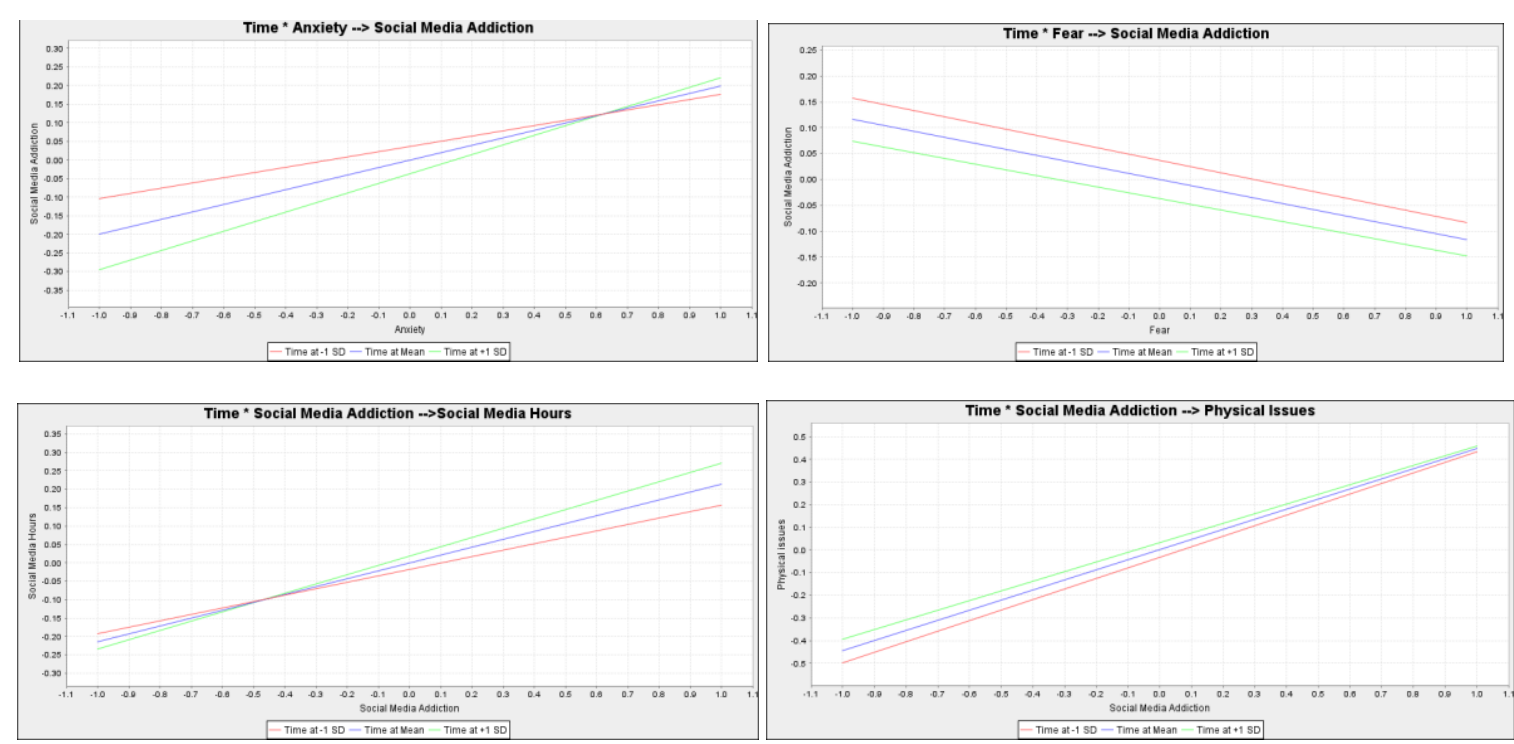

Figure 2: Moderation Effects

To further understand the interaction effects and the changes of the endogenous variables over time, some more figures were created in SPSS. To enable figures using latent constructs, a mean score of the four measurement items of social media addiction was created. This new variable had five values, $0,0.25,0.5,0.75$ and 1 (mean $=0.77, \mathrm{SD}=0.32$ ). As shown in Fig. 3a, participants who reported anxiety always had higher levels of social media addiction. Considering the fluctuation across the six weeks, the social media addiction of participants who had anxiety had an increasing trend over time, and the social media addiction of participants who did not have anxiety had a decreasing trend over time. In contrast, participants who reported fear always had lower levels of social media addiction. The social media addiction level tends to be the same between the beginning and the end of the six weeks (see Fig. 3b).

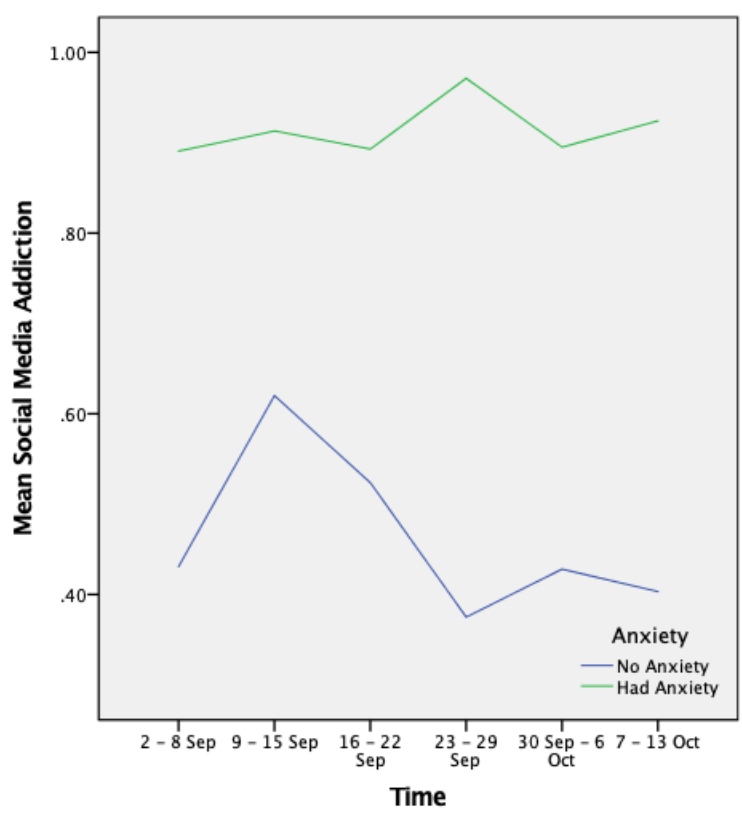

a. Time* Anxiety 4 Social Media Addiction

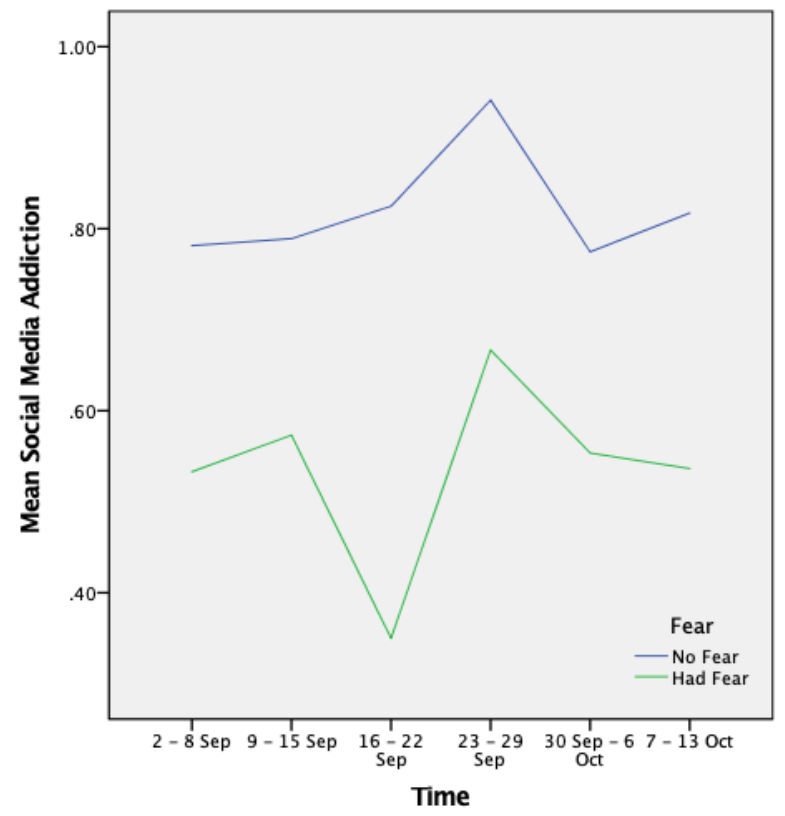

b. Time* Fear पSocial Media Addiction 


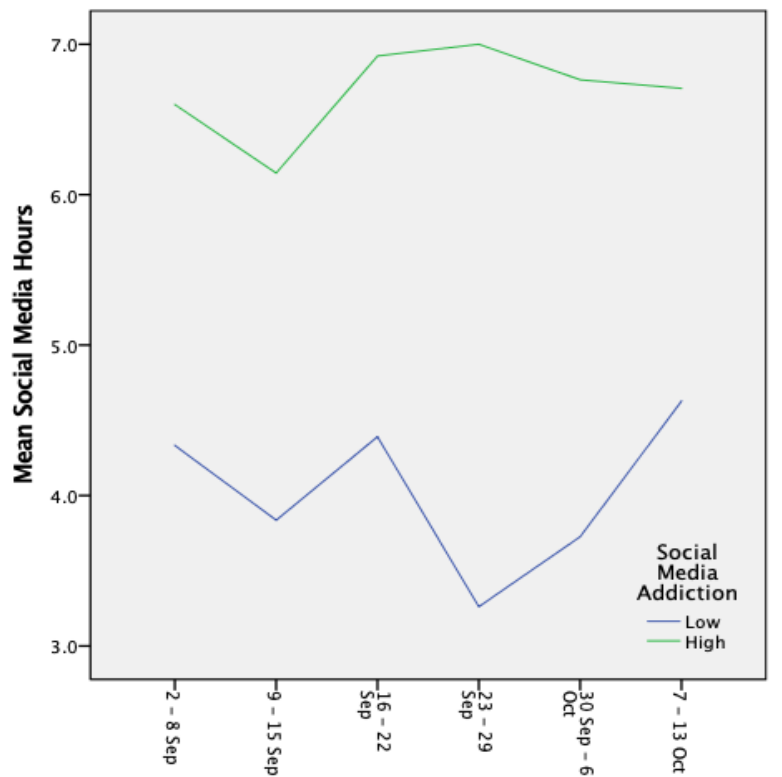

c. Time* Social Media Addiction $\mathrm{C}$ Social Media Hours

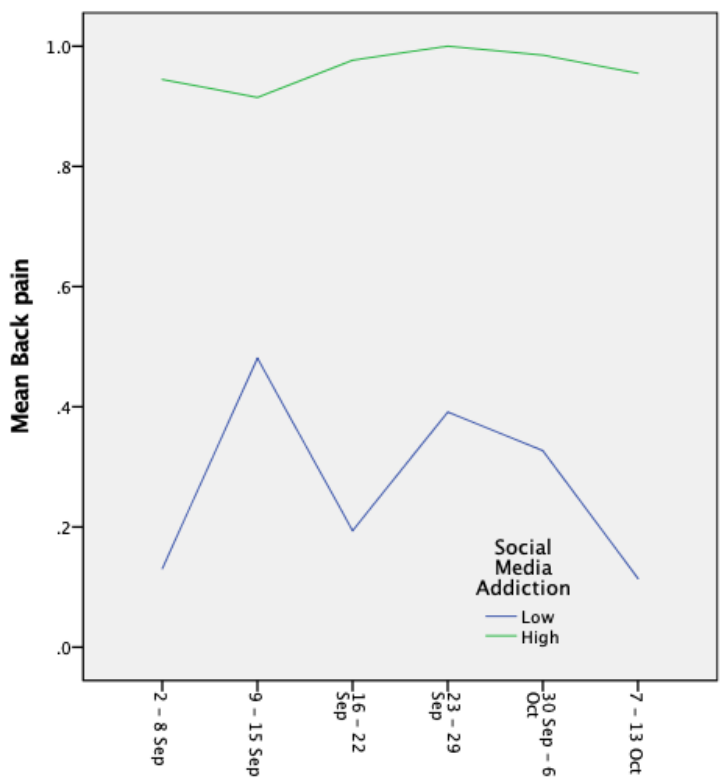

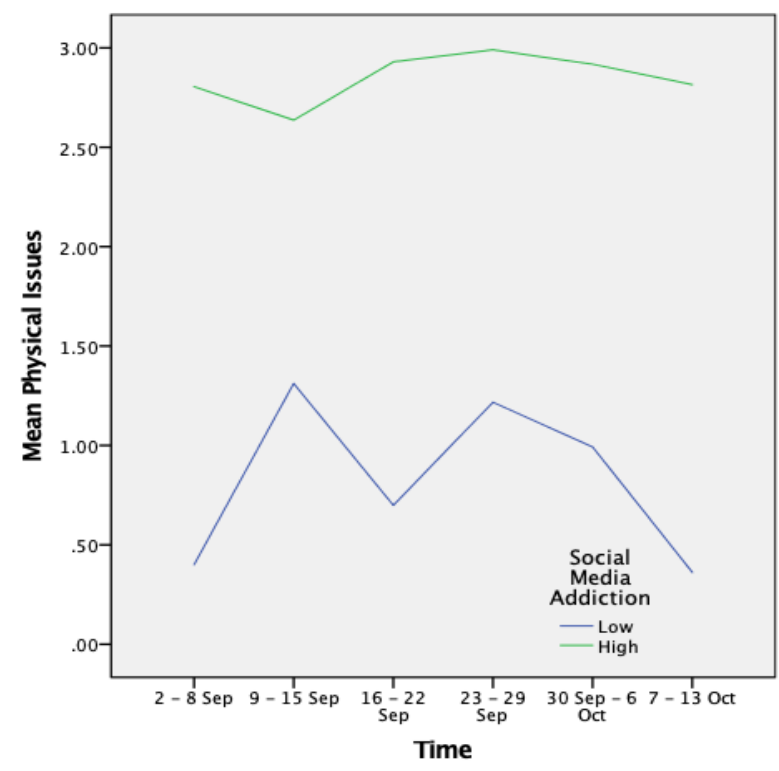

d. Time* Social Media Addiction 0 Physical Issues

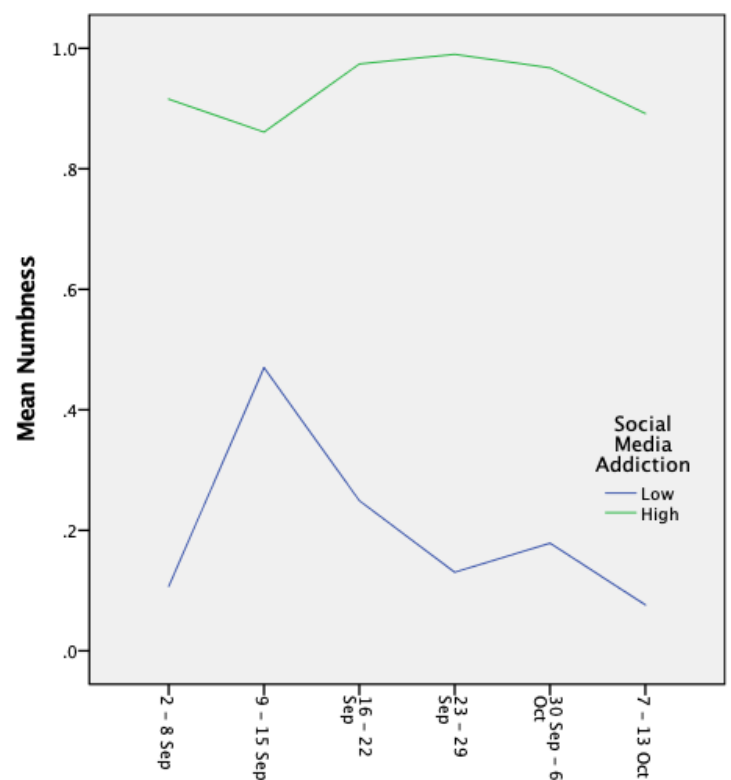

e. Time* Social Media Addiction $\square$ Back Pain f. Time* Social Media Addiction $\mathrm{Q}$ Numbness 


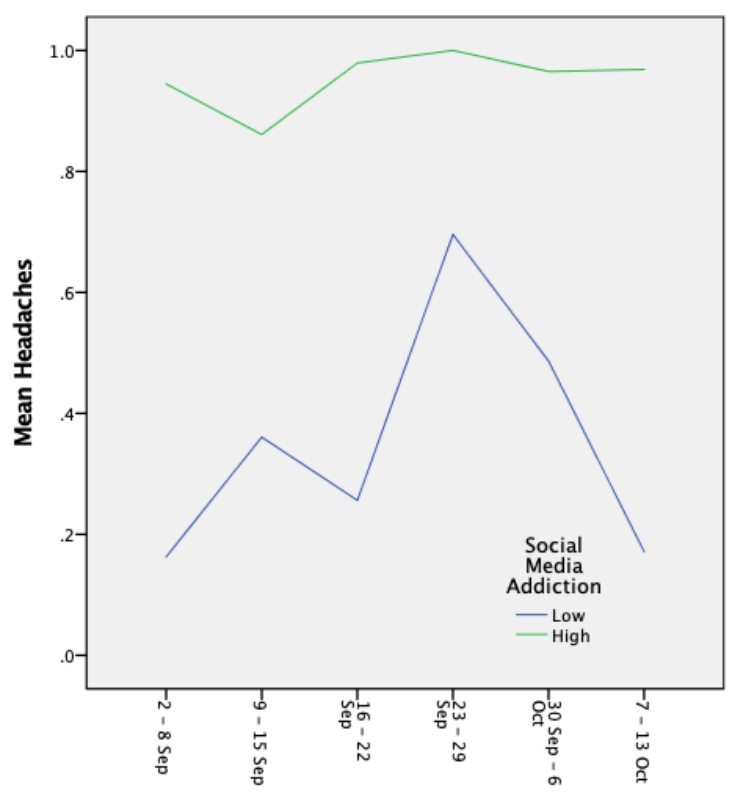

g. Time* Social Media Addiction 0 Headache

Figure 3: Moderation Effects

Social media addiction was split into low $(<=0.75)$, which accounted for $38 \%$, and high $(=1)$, which accounted for $62 \%$. High social media addiction always had higher social media hours (Fig. 3c) and physical issues (Fig. 3d-3g) across the weeks, which confirms the result of $\mathrm{H} 4$.

\section{Discussion}

As addiction is defined as an irrepressible urge that is often accompanied by loss of control, internet addiction leads people to create problems from their uncontrollable abuse of Internet usage, that is related with other pathologies like depression, loneliness and social anxiety [43]. This current study aimed to examine how social media addiction and negative emotions influence health issues after the COVID-19 pandemic lockdown among Bangladeshi workers.

Our study found that the anxiety level of the participants increased over the period of six weeks with the increase of social media addiction, which is in consonance with a past study from Turkey [44], which revealed that University students' social anxiety and happiness significantly forecast their addiction to social media. It is also consistent with several other previous studies [45-47]. This finding may be attributed to the fact that people who communicate difficulties in social environments and opt to create this kind of social interaction by the use of internet tools, portray characteristics of social anxiety [48]. This is further buttressed by a past study [44] which found that happiness significantly forecasts university students' problematic internet use. They espoused that people who are content in their social environment and worry less about being evaluated in this environment normally do not seek different online communication toolsconsequently, the possibility of their being addicted to social media declines.

A study in Bangladesh [49] aimed to assess the prevalence of anxiety among Bangladeshi individuals during the COVID-19 pandemic, vis-a-vis social media exposure (SME) and electronic media exposure (EME), backed the findings of the present study. Another past study revealed that perceived feelings of loneliness predicted both excessive social media use and anxiety, with excessive social media use also increasing anxiety levels [21]. In recent times, the use of social media has been highly lauded to receive health and safety information and ensure that social contacts are maintained to deal with the isolation of the pandemic [50]. Possibly due to the distressing situation, experts have 
suggested social media used to be a transient means of recovery from distress and as a coping strategy. This needs to be conscientiously managed for dealing with loneliness and negative emotions [51]. Consequently, social media and virtual communities enable users to interact with other individuals, strengthen relationships, publicize content, portion out common interests, experiences, and emotions (e.g., [52]), and also enhance their engagement in digital platforms [53]. Nonetheless, there is the risk of social media involvement becoming excessive or dysfunctional by activating a behavior-reward feedback loop [54] which strengthens negative moods and supports a vicious use of social media.

Surprisingly, the present study found a negative association between fear and social media addiction. The study showed that social media addiction decreases users' fear level, and fear level decreases with longer social media hours over the period of six weeks. This might be considered as the benefits of information exchange and peer support. Social media users can receive psychological support and advice from the people who are connected with them, which may help reduce their fear level. Thus, social interaction, through social media, might positively affect the belief, ideas, and thoughts regarding the COVID-19 pandemic, social media use, which can aid in building bridging, bonding, and maintaining social capital [55].

As the strongest factor, "working hours"is positively correlated with social media hours, social media addiction, and physical problems. The significance of this finding is that working professionals who are involved in social media usage during working hours are likely to be preoccupied with sustaining a sustained link with social media to make sure that they take part in all rewarding experiences being shared on these platforms. Eventually, such people exhibit decreased work efficiency (both decisional and action) and a reduction in work performance. Accordingly, our finding could be explained through the tenets of the limited capacity model [56], because of the fact that internet usage may burden the capacity of an individual to process information. Because of this burdened capacity, such users would not efficiently process work-related information and delay making decisions or executing work-related tasks. That is to say, working professionals' internet usage during working hours may hinder their intellectual processing ability and redirect them from achieving their primary work tasks, resulting in reduced reported work performance decrement. Our finding aligns with that of past studies, which indicate that daily social media use during working hours is a distraction which has a negative impact on employees' work performance [57]. The significant association between social media usage and hesitation is a new addition to the extant literature. It reveals that social media usage during working hours can impact the decision-making ability and work efficiency of an individual, which, to our knowledge, has not been examined before.

On the contrary, other control variables such as leisure time, gender, education level and age are directly or indirectly negatively associated with physical issues. The study found that social media users with longer leisure time, higher education, and females have fewer physical problems caused by social media usage. Our finding of the association of social media users with longer leisure time and physical activity demonstrates that there is a greater likelihood of engaging against not engaging in all three types of physical activity among internet users than among those who do not use the internet. Moreover, the results show that, contradictory to presumptions that spending a long time sitting at the computer may result in a sedentary lifestyle; weekly hours spent online were not significant predictors of the likelihood of engaging versus not engaging in physical activity. The results suggest a possible relationship between other Internet use components and physical activity.

Our finding of the association between social media users with higher education and physical activity suggests that there is a correlation between internet usage for studying and physical activity on the one hand, and between internet usage and social media on the other, suggesting that both studying and social media empower individuals to access information which could help them to develop particular plans for physical activity 
customized to their needs, perceptions, and abilities, whether strenuous or moderate. With regards to physical exercise to strengthen muscles, the particular digital uses, seeking information and playing games were identified as those which correlated with this type of physical activity. Looking for information is another activity which suggests a need for acquisition of knowledge and being competent in making plans about physical activity [58] independently.

The association between female social media users and physical activity showed that females had a stronger insight of ease of use, compatibility, relative advantage, and risk when they use social media, in comparison to men. More recent research, for instance, one by Lin and Wang [59] aimed to explain the differences in gender in information-sharing behavior on social networking sites. To accomplish this, a comparative theoretical model of information sharing between genders was established. Consistent with past research, analysis revealed a greater importance of privacy risk, social ties, and commitment for women than men, because attitude towards information sharing impacts people's intention to share information more strongly for women than it does for men. Another recent research [60] made an attempt to examine gender differences in the use of social media by investigating adolescents aged 13-18 years in the U.S. and UK. Results showed that adolescent girls spent more time on smartphones, social media, texting, general computer use, compared with boys. However, no further assessment was conducted to ascertain how much of this time was spent to plan an activity.

Moreover, older people are less addicted to social media, causing fewer physical disorders. We observed that females were less addicted to social media than their male counterparts, and therefore are particularly less vulnerable regarding physical issues caused by social media addiction. Hence, it can be summarized that generally, males with long working hours spend more time on social media and become addicted to it and consequently become victims of several physical disorders.

As discussed above, there exists a positive association between social media usage hours and social media addiction level. Therefore, we can combine the terms like social media addiction to discuss the effects of social media usage hours and its effect on physical issues and the effect of social media addiction on physical issues. Our study found that several physical problems related to physical issues increase with the increase of social media addiction levels. Several studies support the findings of the present study. For instance, a study in Iran [61] proposed a possible psychopathology mechanism to elucidate psychological distress among Iranian young adults during the COVID-19 public health crisis. There was a significant association between problematic social media use and psychological distress, both directly and indirectly.

Moreover, the themes which emerged from a study [62] which aimed to obtain an accurate understanding into employees' experiences concerning their usage of social media and repercussions of social media overuse at the workplace in renowned Information Technology/Information Technology enabled Services (IT/ITES) companies in India were: sleep deprivation; lumbago and eye strain; feeling of envy; lack of depth in the relationships; tendency to seek approvals; not meeting deadlines; compromise with the work quality; a distraction from work. Another study among social media users observed a number of physical, psychological and behavioral issues. Frequently seen physical problems included a strain on eyes, neck pain, back pain, headache, watering of eyes, wrist and shoulder pain, which were consistent with other studies [63]. However, some exogenous variables were also considered to see if any external factors influence the association between Internet addiction and physical issues in this study. The study found that "working hours" only positively correlated with physical issues.

There is a stronger role that social media could play, that could enable us to treat socially-shaped diseases like obesity, depression, diabetes, heart disease, and other mental illnesses. A past study [64] outlined how social network thinking is growing, and described several current uses of social media in healthcare before describing how we could harness the understanding of social networks and media for this stronger role of treating socially physical and psychological diseases. However, every aspect of daily 
living has been disrupted by the COVID-19 pandemic, giving rise to forced isolation and practicing social distancing, economic difficulty, fears of being infected by a potentially fatal illness that could make a person feel helpless and hopeless [65]. Past research [66] expressed concern about the way and manner individuals have endured in the past so as to identify strategies which could be especially successful in controlling health issues and developing resilience during critical times.

Notwithstanding the fact that this current study was systematically designed, it was limited in a number of ways. Firstly, our results were based on only workers in government and non-government companies. Secondly, the study covered only workers aged between 25 and 45 years. Due to the fact that the PLS-SEM technique is new and easy to implement, we can extend the study to assess the influence of the pandemic lockdown on other aspects of life other than health, people aged outside the age bracket 25-45 years. Thirdly, despite the fact that research on the PLS-SEM method has gained popularity in the last ten years, there are sufficient research opportunities on subjects like mediation or multi-group analysis, which necessitate further investigation.

\section{Conclusions}

The study is potentially significant because it will offer social media users, healthcare workers, and policymakers' insights into the adverse effect of addictive social media use. Most importantly, it will highlight the association of social media addiction with different issues related to our work, health, education, age, working hours, leisure time and gender, the very important issues at the center of life.

Author Contributions: Conceptualization: Tanvir Abir and Dewan Md Nur -A Yazdani; Data Curation: Kingsley Ago and Tanvir Abir; Analysis: Kingsley Ago, Tanvir Abir and Shasha Wang, Methodology: Kingsley Ago, Tanvir Abir, Shasha Wang and Abdullah Al Mamun, Drafting of the manuscript: Dewan Md Nur -A Yazdani, Jamee Ahmed, Yang Qing, and Kaniz Kakon; Supervision: Noor Raihani Zainol; Statistical analysis: Kingsley Ago and Tanvir Abir; Revision of the manuscript: All authors.

Funding: "This research received no external funding".

Institutional Review Board Statement: The Institutional Review Board of the International University of Business, Agriculture and Technology (IUBAT), Dhaka, Bangladesh, granted permission for this study (IUBAT/AR/2021/002). The study followed the principles of the Helsinki Declaration, as updated in Fortaleza.

Informed Consent Statement: Before completing the questionnaire, all participants were informed about the study's specific goal, and consent was obtained from all participants through an online preamble. To avert repeated responses, and also to make sure that the data were valid to some extent, respondents were permitted to complete the survey only once; this was because of the fact that data were limited to their IP addresses and device. Respondents had the option of terminating the survey at any time they desired. Furthermore, we ensured that the data were anonymous and confidential.

Data Availability Statement: Data can be available upon request.

Acknowledgments: None to declare.

Conflicts of Interest: “The authors declare no conflict of interest.”.

\section{References}

1. Available online: http://www.internetworldstats.com/emarketing.htm. (accessed on 30 January 2022).

2. Mazumdar, A.; Alharahsheh, H.H. Digital Bangladesh-Vision 2021: What Is the Digital Bangladesh Concept. South Asian Research Journal of Engineering and Technology 2020, 2, 6-9.

3. Sushama, C.; Sunil Kumar, M.; Neelima, P. Privacy and Security Issues in the Future: A Social Media. Mater. Today 2021, doi:10.1016/j.matpr.2020.11.105. 
4. Laguna, L.; Fiszman, S.; Puerta, P.; Chaya, C.; Tárrega, A. The Impact of COVID-19 Lockdown on Food Priorities. Results from a Preliminary Study Using Social Media and an Online Survey with Spanish Consumers. Food Qual. Prefer. 2020, 86, 104028, doi:10.1016/j.foodqual.2020.104028.

5. Barrett-Maitland, N.; Lynch, J. Social Media, Ethics and the Privacy Paradox. Security and Privacy from a Legal, Ethical, and Technical Perspective; 2019;

6. Suh, S. Non-Boundaries of Style Represented in Fashion Instagram: A Social Media Platform as a Digital Space-Time. Fashion and Textiles. 2020, 7, 1-32.

7. Anwar, S.; Nasrullah, M.; Hosen, M.J. COVID-19 and Bangladesh: Challenges and How to Address Them. Front. Public Health 2020, 8, 154, doi:10.3389/fpubh.2020.00154.

8. Hu, Z.; Song, C.; Xu, C.; Jin, G.; Chen, Y.; Xu, X.; Ma, H.; Chen, W.; Lin, Y.; Zheng, Y.; et al. Clinical Characteristics of 24 Asymptomatic Infections with COVID-19 Screened among Close Contacts in Nanjing, China. Sci. China Life Sci. 2020, 63, 706-711, doi:10.1007/s11427-020-1661-4.

9. Islam, M.S.; Ferdous, M.Z.; Potenza, M.N. Panic and Generalized Anxiety during the COVID-19 Pandemic among Bangladeshi People: An Online Pilot Survey Early in the Outbreak. J. Affect. Disord. 2020, 276, 30-37, doi:10.1016/j.jad.2020.06.049.

10. Ammar, A.; Chtourou, H.; Boukhris, O.; Trabelsi, K.; Masmoudi, L.; Brach, M.; Bouaziz, B.; Bentlage, E.; How, D.; Ahmed, M.; et al. COVID-19 Home Confinement Negatively Impacts Social Participation and Life Satisfaction: A Worldwide Multicenter Study. Int. J. Environ. Res. Public Health 2020, 17, 6237, doi:10.3390/ijerph17176237.

11. Zhao, H.; Liu, F.; Xie, W.; Zhou, T.-C.; OuYang, J.; Jin, L.; Li, H.; Zhao, C.-Y.; Zhang, L.; Wei, J.; et al. Ultrasensitive Supersandwich-Type Electrochemical Sensor for SARS-CoV-2 from the Infected COVID-19 Patients Using a Smartphone. Sens. Actuators B Chem. 2021, 327, 128899, doi:10.1016/j.snb.2020.128899.

12. Kirik, A.; Arslan, A.; Çetinkaya, A.; Mehmet, G.Ü.L. A Quantitative Research on the Level of Social Media Addiction among Young People in Turkey. International Journal of Sport Culture and Science 2015, 3, 108-122.

13. Afacan, O.; Ozbek, N. Investigation of Social Media Addiction of High School Students. Int. J. Educ. Method. 2019, 5, 235-245, doi:10.12973/ijem.5.2.235.

14. Kuss, D.J.; Griffiths, M.D. Social Networking Sites and Addiction: Ten Lessons Learned. Int. J. Environ. Res. Public Health 2017, 14, doi:10.3390/ijerph14030311.

15. Bisen, S.S.; Deshpande, Y.M. Understanding Internet Addiction: A Comprehensive Review. Ment. Health Rev. (Brighton) 2018, 23, 165-184, doi:10.1108/mhrj-07-2017-0023.

16. Azizi, S.M.; Soroush, A.; Khatony, A. The Relationship between Social Networking Addiction and Academic Performance in Iranian Students of Medical Sciences: A Cross-Sectional Study. BMC Psychol. 2019, 7, 28, doi:10.1186/s40359-019-0305-0.

17. Hussain, Z.; Griffiths, M.D. The Associations between Problematic Social Networking Site Use and Sleep Quality, Attention-Deficit Hyperactivity Disorder, Depression, Anxiety and Stress. Int. J. Ment. Health Addict. 2021, 19, 686-700, doi:10.1007/s11469-019-00175-1.

18. Majumdar, P.; Biswas, A.; Sahu, S. COVID-19 Pandemic and Lockdown: Cause of Sleep Disruption, Depression, Somatic Pain, and Increased Screen Exposure of Office Workers and Students of India. Chronobiol. Int. 2020, 37, 1191-1200, doi:10.1080/07420528.2020.1786107.

19. Cellini, N.; Canale, N.; Mioni, G.; Costa, S. Changes in Sleep Pattern, Sense of Time and Digital Media Use during COVID-19 Lockdown in Italy. J. Sleep Res. 2020, 29, e13074, doi:10.1111/jsr.13074.

20. Sivertsen, B.; Vedaa, Ø.; Harvey, A.G.; Glozier, N.; Pallesen, S.; Aarø, L.E.; Lønning, K.J.; Hysing, M. Sleep Patterns and Insomnia in Young Adults: A National Survey of Norwegian University Students. J. Sleep Res. 2019, 28, e12790, doi:10.1111/jsr.12790.

21. Naslund, J.A.; Bondre, A.; Torous, J.; Aschbrenner, K.A. Social Media and Mental Health: Benefits, Risks, and Opportunities for Research and Practice. J. Technol. Behav. Sci. 2020, 5, 245-257, doi:10.1007/s41347-020-00134$\mathrm{x}$.

22. Goyal, P.; Choi, J.J.; Pinheiro, L.C.; Schenck, E.J.; Chen, R.; Jabri, A.; Satlin, M.J.; Campion, T.R., Jr; Nahid, M.; Ringel, J.B.; et al. Clinical Characteristics of Covid-19 in New York City. N. Engl. J. Med. 2020, 382, 2372-2374, doi:10.1056/NEJMc2010419. 
23. Wang, C.; Pan, R.; Wan, X.; Tan, Y.; Xu, L.; McIntyre, R.S.; Choo, F.N.; Tran, B.; Ho, R.; Sharma, V.K.; et al. A Longitudinal Study on the Mental Health of General Population during the COVID-19 Epidemic in China. Brain Behav. Immun. 2020, 87, 40-48, doi:10.1016/j.bbi.2020.04.028.

24. Qiu, J.; Shen, B.; Zhao, M.; Wang, Z.; Xie, B.; Xu, Y. A Nationwide Survey of Psychological Distress among Chinese People in the COVID-19 Epidemic: Implications and Policy Recommendations. Gen Psychiatr 2020, 33, e100213, doi:10.1136/gpsych-2020-100213.

25. Islam, M.S.; Sujan, M.S.H.; Tasnim, R.; Mohona, R.A.; Ferdous, M.Z.; Kamruzzaman, S.; Toma, T.Y.; Sakib, M.N.; Pinky, K.N.; Islam, M.R.; et al. Problematic Smartphone and Social Media Use among Bangladeshi College and University Students amid COVID-19: The Role of Psychological Well-Being and Pandemic Related Factors. Front. Psychiatry 2021, 12, 647386, doi:10.3389/fpsyt.2021.647386.

26. Ahorsu, D.K.; Lin, C.-Y.; Pakpour, A.H. The Association between Health Status and Insomnia, Mental Health, and Preventive Behaviors: The Mediating Role of Fear of COVID-19. Gerontol. Geriatr. Med. 2020, 6, 2333721420966081, doi:10.1177/2333721420966081.

27. Burke, J.; Arslan, G. Positive Education and School Psychology during COVID-19 Pandemic. Journal of Positive School Psychology 2020, 4, 137-139, doi:10.47602/jpsp.v4i2.243.

28. Yıldırım, M.; Güler, A. COVID-19 Severity, Self-Efficacy, Knowledge, Preventive Behaviors, and Mental Health in Turkey. Death Stud. 2020, 1-8, doi:10.1080/07481187.2020.1793434.

29. Pennycook, G.; McPhetres, J.; Zhang, Y.; Lu, J.G.; Rand, D.G. Fighting COVID-19 Misinformation on Social Media: Experimental Evidence for a Scalable Accuracy-Nudge Intervention. Psychol. Sci. 2020, 31, 770-780, doi:10.1177/0956797620939054.

30. Montemurro, N. The Emotional Impact of COVID-19: From Medical Staff to Common People. Brain Behav. Immun. 2020, 87, 23-24, doi:10.1016/j.bbi.2020.03.032.

31. Erbaş, Ü.; Üniversity, Ş.; Gümüş, H.; Üniversity, M. Participation in Physical Activity and Social Media Addiction in Students. Int. j. psychol. educ. stud. 2020, 7, 52-60, doi:10.17220/ijpes.2020.04.006.

32. Van Rooij, A.J.; Prause, N. A Critical Review of "Internet Addiction" Criteria with Suggestions for the Future. J. Behav. Addict. 2014, 3, 203-213, doi:10.1556/JBA.3.2014.4.1.

33. Hair, J.F.; Ringle, C.M.; Sarstedt, M. Partial Least Squares: The Better Approach to Structural Equation Modeling? Long Range Plann. 2012, 45, 312-319, doi:10.1016/j.lrp.2012.09.011.

34. Hair, J.F.; Risher, J.J.; Sarstedt, M.; Ringle, C.M. When to Use and How to Report the Results of PLS-SEM. European Business Review; 2019;

35. Malak, M.Z.; Shuhaiber, A.H.; Al-amer, R.M.; Abuadas, M.H.; Aburoomi, R.J. Correlation between Psychological Factors, Academic Performance and Social Media Addiction: Model-Based Testing. Behav. Inf. Technol. 2021, 1-13, doi:10.1080/0144929x.2021.1891460.

36. Henseler, J.; Ringle, C.M.; Sarstedt, M. A New Criterion for Assessing Discriminant Validity in VarianceBased Structural Equation Modeling. J. Acad. Mark. Sci. 2015, 43, 115-135, doi:10.1007/s11747-014-0403-8.

37. Caplan, S.E. Theory and Measurement of Generalized Problematic Internet Use: A Two-Step Approach. Comput. Human Behav. 2010, 26, 1089-1097, doi:10.1016/j.chb.2010.03.012.

38. Cheung, G.W.; Wang, C. Current Approaches for Assessing Convergent and Discriminant Validity with SEM: Issues and Solutions. Acad. Manag. Proc. 2017, 2017, 12706, doi:10.5465/ambpp.2017.12706abstract.

39. Henseler, J.; Dijkstra, T.K.; Sarstedt, M.; Ringle, C.M.; Diamantopoulos, A.; Straub, D.W.; Calantone Common Beliefs and Reality about PLS: Comments on Rönkkö and Evermann (2013). Organizational research methods 2013, 17, 182-209.

40. Miles, J. Tolerance and Variance Inflation Factor; 2014;

41. Kumar, D.S.; Purani, K. Model Specification Issues in PLS-SEM: Illustrating Linear and Non-Linear Models in Hospitality Services Context. Journal of Hospitality and Tourism Technology 2018.

42. Geisser, S. A Predictive Approach to the Random Effect Model. Biometrika 1974, 61, 101, doi:10.2307/2334290.

43. Caplan, S.E.; High, A.C. Online Social Interaction, Psychosocial Well-Being, and Problematic Internet Use. In Internet Addiction; John Wiley \& Sons, Inc.: Hoboken, NJ, USA, 2012; pp. 35-53 ISBN 9781118013991.

44. Baltac1, Ö.; Ahi Evran University The Predictive Relationships between the Social Media Addiction and Social Anxiety, Loneliness, and Happiness. Int. J. Prog. Educ. 2019, 15, 73-82, doi:10.29329/ijpe.2019.203.6. 
45. Doğan, U.; İlçïn Tosun, N. LİSE ÖĞRENCILERİNDE PROBLEMLİ AKILLI TELEFON KULLANIMININ SOSYAL KAYGI VE SOSYAL AĞLARIN KULLANIMINA ARACILIK ETKİSİ. Adıyaman üniv. sos. bilim. enst. derg. 2016, 1, 99, doi:10.14520/adyusbd.66762.

46. Ko, C.H.; Yen, J.Y.; Yen, C.F.; Chen, C.S.; Chen, C.C. The Association between Internet Addiction and Psychiatric Disorder: A Review of the Literature. Eur. Psychiatry 2012, 27, 1-8, doi:10.1016/j.eurpsy.2010.04.011.

47. Yen, J.-Y.; Yen, C.-F.; Chen, C.-S.; Wang, P.-W.; Chang, Y.-H.; Ko, C.-H. Social Anxiety in Online and RealLife Interaction and Their Associated Factors. Cyberpsychol. Behav. Soc. Netw. 2012, 15, 7-12, doi:10.1089/cyber.2011.0015.

48. Valkenburg, P.M.; Peter, J.; Schouten, A.P. Friend Networking Sites and Their Relationship to Adolescents' Well-Being and Social Self-Esteem. Cyberpsychol. Behav. 2006, 9, 584-590, doi:10.1089/cpb.2006.9.584.

49. Hossain, M.T.; Ahammed, B.; Chanda, S.K.; Jahan, N.; Ela, M.Z.; Islam, M.N. Social and Electronic Media Exposure and Generalized Anxiety Disorder among People during COVID-19 Outbreak in Bangladesh: A Preliminary Observation. PLoS One 2020, 15, e0238974, doi:10.1371/journal.pone.0238974.

50. Available online: https://www.apa.org/topics/covid-19/view-coverage (accessed on 30 January 2022).

51. Wiederhold, B.K. Using Social Media to Our Advantage: Alleviating Anxiety during a Pandemic. Cyberpsychol. Behav. Soc. Netw. 2020, 23, 197-198, doi:10.1089/cyber.2020.29180.bkw.

52. Boursier, V.; Manna, V.; Gioia, F.; Coppola, F.; Venosa, N. Cyber-Moms Facing Motherhood: Holding Functions and Regressive Movements in Parenting Websites. In Innovations in Global Maternal Health: Improving Prenatal and Postnatal Care Practices; IGI Global, 2020; pp. 80-108.

53. Perloff, R.M. Social Media Effects on Young Women's Body Image Concerns: Theoretical Perspectives and an Agenda for Research. Sex Roles 2014, 71, 363-377, doi:10.1007/s11199-014-0384-6.

54. Yao, M.Z.; Zhong, Z.-J. Loneliness, Social Contacts and Internet Addiction: A Cross-Lagged Panel Study. Comput. Human Behav. 2014, 30, 164-170, doi:10.1016/j.chb.2013.08.007.

55. Burke, M.; Kraut, R.E. Growing Closer on Facebook: Changes in Tie Strength through Social Network Site Use. In Proceedings of the SIGCHI conference on human factors in computing systems; 2014; pp. 4187-4196.

56. Lang, A. The Limited Capacity Model of Mediated Message Processing. J. Commun. 2000, 50, 46-70, doi:10.1111/j.1460-2466.2000.tb02833.x.

57. Lee, S.Y.; Lee, S.W. The Effect of Facebook Use on Office Workers' Job Performance and the Moderating Effects of Task Equivocality and Interdependence. Behav. Inf. Technol. 2018, 37, 828-841, doi:10.1080/0144929x.2018.1485743.

58. Zach, S.; Lissitsa, S. Internet Use and Leisure Time Physical Activity of Adults-A Nationwide Survey. Computers in Human Behavior 2016, 60, 483-491.

59. Lin, X.; Wang, X. Examining Gender Differences in People's Information-Sharing Decisions on Social Networking Sites. Int. J. Inf. Manage. 2020, 50, 45-56, doi:10.1016/j.ijinfomgt.2019.05.004.

60. Twenge, J.M.; Martin, G.N. Gender Differences in Associations between Digital Media Use and Psychological Well-Being: Evidence from Three Large Datasets. J. Adolesc. 2020, 79, 91-102, doi:10.1016/j.adolescence.2019.12.018.

61. Lin, C.-Y.; Imani, V.; Majd, N.R.; Ghasemi, Z.; Griffiths, M.D.; Hamilton, K.; Hagger, M.S.; Pakpour, A.H. Using an Integrated Social Cognition Model to Predict COVID-19 Preventive Behaviours. Br. J. Health Psychol. 2020, 25, 981-1005, doi:10.1111/bjhp.12465.

62. Priyadarshini, C.; Dubey, R.K.; Kumar, Y.L.N.; Jha, R.R. Impact of a Social Media Addiction on Employees' Wellbeing and Work Productivity. The Qualitative Report 2020, 25, 181-196.

63. Usgaonkar, U.; Shet Parkar, S.R.; Shetty, A. Impact of the Use of Digital Devices on Eyes during the Lockdown Period of COVID-19 Pandemic. Indian J. Ophthalmol. 2021, 69, 1901-1906, doi:10.4103/ijo.IJO_3500_20.

64. Coiera, E. Social Networks, Social Media, and Social Diseases. BMJ 2013, 346, f3007, doi:10.1136/bmj.f3007.

65. Abir, T.; Kalimullah, N.A.; Osuagwu, U.L.; Yazdani, D.M.N.-A.; Mamun, A.A.; Husain, T.; Basak, P.; Permarupan, P.Y.; Agho, K.E. Factors Associated with the Perception of Risk and Knowledge of Contracting the SARS-Cov-2 among Adults in Bangladesh: Analysis of Online Surveys. Int. J. Environ. Res. Public Health 2020, 17, 5252, doi:10.3390/ijerph17145252. 
66. Polizzi, C.; Lynn, S.J.; Perry, A. Stress and Coping in the Time of Covid-19: Pathways to Resilience and Recovery. Clin. Neuropsychiatry 2020, 17, 59-62, doi:10.36131/CN20200204. 